\title{
Oksygen til nyfødte?
}

\author{
Oksygenbehandling har vært brukt ukritisk til for tidlig fødte barn og ved resuscitering av nyfødte og har \\ ført til mange iatrogene skader. Mest kjent er epidemien med kuvøseblindhet i 1940-årene. Fortsatt er man \\ usikker på hva som er den optimale oksygenmetningen til for tidlig fødte barn de første ukene etter fødselen. \\ I nye internasjonale retningslinjer er det slått fast at det er best å starte med luft i stedet for 100 \% oksygen \\ ved resuscitering av nyfødte født til termin.
}

Podkast til artikkel www.tidsskriftet.no/podkast

\section{Ola Didrik Saugstad}

odsaugstad@rr-research.no

Pediatrisk forskningsinstitutt

Kvinne-barn-klinikken

Oslo universitetssykehus, Rikshospitalet

Tilførsel av oksygen er en av de vanligste behandlinger av nyfødte, spesielt av dem som er født for tidlig. Etter en epidemi med det som ble kalt kuvøseblindhet og som i dag kalles prematuritetsretinopati (retinopathy of prematurity) forsto man i 1950 årene at oksygen kan være skadelig for premature (1). Prematuritetsretinopati var en ny sykdom som oppsto i 1940-årene i en tid da det var standardbehandling å gi for tidlig fødte kontinuerlig tilførsel av oksygen. I slutten av 1960-årene oppdaget man enda en iatrogen sykdom som rammer for tidlig fødte barn, lungesykdommen bronkopulmonal dysplasi. Man forsto raskt at årsaken til bronkopulmonal dysplasi blant annet var at for tidlig fødte barn blir behandlet med oksygen (2).

Allerede i 1780, bare noen år etter at oksygen ble beskrevet som et grunnstoff av Carl Wilhelm Scheele og Joseph Priestley, ble det brukt i behandlingen av nyfødte (3). Utover på 1800-tallet begynte man å forstå at oksygen også kan være skadelig for en rekke organer. I 1950-årene lanserte Rebecca Gerschman og medarbeidere hypotesen at oksygentoksisitet og radioaktiv strålingsskade skyldes samme mekanisme: produksjonen av frie radikaler. Likevel klarte man ikke i 1950- og 1960-årene å kontrollere og redusere forekomsten av prematuritetsretinopati og etter hvert bronkopulmonal dysplasi. Tvert om har det vært en stor økning i forekomsten av prematuritetsretinopati utover i 1970-årene, da man fikk svært umodne barn til å overleve. Så mange som 50000 barn blir kanskje fortsatt blinde på verdensbasis hvert år på grunn av prematuritetsretinopati (4).
I 1980-årene begynte man å forstå at for tidlig fødte barn ikke hadde samme forsvarsmidler mot oksidativt stress som barn født til termin, og kanskje vel så viktig, man begynte å forstå at det er en rekke faktorer, i tillegg til oksygennivået, som bidrar til oksidativt stress hos disse barna. Da vi introduserte begrepet oksygenradikalsykdom hos nyfødte (oxygen radical disease of the newborn) (5), bidro dette til en sterkt økende interesse for betydningen av oksidativt stress hos for tidlig fødte barn. Samtidig ble puls-

\section{«Oksygenbehandling av nyfødte har en lang og til dels smertelig historie»}

oksymetrene introdusert i den kliniske hverdagen. Dette ga muligheten til en kontinuerlig ikke-invasiv overvåking av oksygenmetningen til syke nyfødte. Men det tok flere år før man skjønte hva som er normalverdier for disse barna.

Det er nå 60 år siden man forsto at langvarig oksygenbehandling kan være skadelig for premature, men man trodde ikke at kortvarig oksygenbehandling av barn født til termin er det. I forbindelse med resuscitering av nyfødte født til termin begynte man tidlig å bruke $100 \%$ oksygen som standardbehandling (3). I internasjonale retningslinjer het det så sent som i 1992 at det ikke er grunn til å være bekymret over at tilførselen av $100 \%$ oksygen kan være skadelig den korte tiden en resuscitering etter fødselen foregår (6). Men så har det vist seg at også det var en feilantakelse. I 2010 ble de internasjonale retningslinjene endret. Nå heter det at «det er best å begynne med luft ved gjenoppliving av barn født til termin eller nær termin» (7).

\section{Oksygenmetningen \\ hos for tidlig fødte}

I 2001 publiserte Tin og medarbeidere en observasjonsstudie fra fire nyfødtavdelinger i Storbritannia (8). De fant at avdelingene brukte forskjellige alarmgrenser for oksygenmetningen til barn født før 28. svangerskapsuke. Den avdelingen som brukte de høyeste alarmgrensene (88-98\%), hadde fire ganger så mye alvorlig prematuritetsretinopati som den avdelingen som brukte de laveste grensene (70-90\%). De to avdelingene med alarmgrenser mellom disse hadde en forekomst av alvorlig prematuritetsretinopati mellom ytterpunktene. Det var også mer lungeproblemer og større behov for respiratorbehandling blant barna som fikk mest oksygen. I en nylig systematisk gjennomgang av litteraturen fant vi at forekomsten av alvorlig prematuritetsretinopati er halvert hos for tidlig fødte barn hvor man tilstrebet såkalt lav oksygenmetning i forhold til dem med høy oksygenmetning (9). Forekomsten av bronkopulmonal dysplasi og/eller lungeskade ble redusert med 20-25\% i lavoksygengruppen. De fleste anbefalinger har derfor de siste årene vært at for tidlig fødte skal ha en oksygenmetning mellom $85 \%$ og $93 \%$ (10).

Flere store randomiserte studier ble startet hvor man undersøker effekten av høy (dvs. 91-95\%) i forhold til lav (85-89\%) oksygenmetning hos barn født før 28 ukers svangerskap. Den første av disse studiene, den nord-amerikanske SUPPORT-studien, ble publisert i 2010 (11). Den omfattet 1316 barn født mellom 24. og 28. svangerskapsuke. Forekomsten av alvorlig prematuritetsretinopati ble halvert blant barn som ble behandlet $\mathrm{i}$ lavoksygengruppen. I tillegg fant man en signifikant økt dødelighet i lavoksygengruppen i forhold til høyoksygengruppen (19,9\% versus 16,2\%). Det gir en relativ risiko for død på $1,27(95 \%$ KI 1,01-1,60). Dette skapte uro i verdens nyfødtmedisinske miljøer. Men så lenge de andre store studiene fortsatte, ville de fleste vente med å trekke konklusjoner, og de 


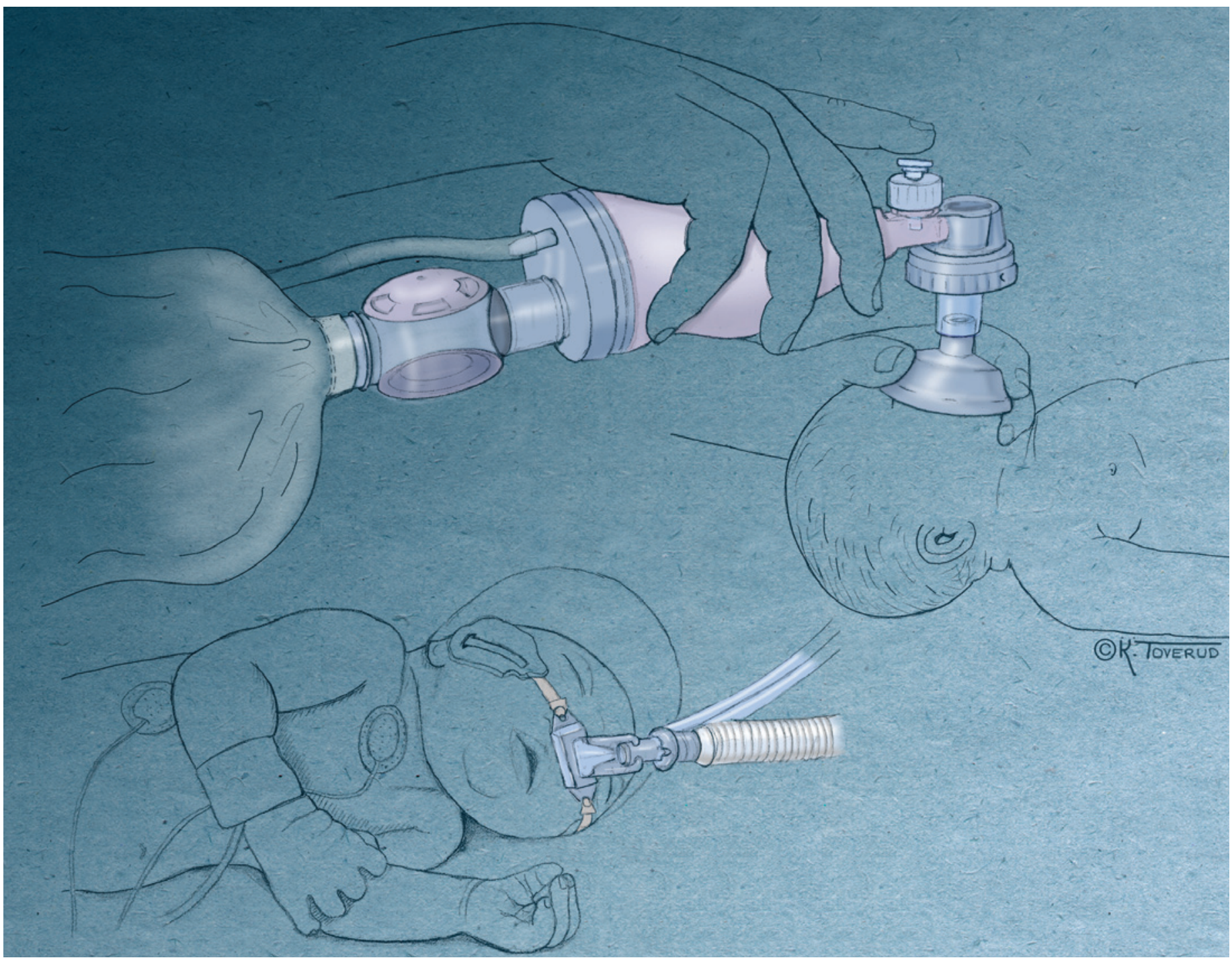

Oksygen kan tilføres nyfødte både ved hjelp av bag og maske (øverst) og nese-CPAP (nederst). I dag anbefales det å starte med luft til barn født til termin eller nær termin som trenger pustehjelp ved fødselen

fleste fortsatte å styre oksygenmetningen mellom $85 \%$ og $93 \%$.

Vinteren 2011 ble det en rask og dramatisk utvikling i feltet. Først publiserte deltakere i en av de andre pågående store kliniske studiene, BOOST II-studien, at algoritmen som ble brukt i det kommersielle pulsoksymeteret i de store studiene, var feil (12). Noen måneder senere, i juni 2011, ble det så kjent at BOOST II-studien var blitt stoppet. Tidligere hadde man ikke funnet forskjeller i dødelighet mellom de to gruppene. Men ved å bruke en ny og mer korrekt algoritme, hadde man på nytt regnet på overlevelsen mellom høyoksygen- og lavoksygengruppene. Data om 2315 barn i studien ble slått sammen med resultatene fra SUPPORT-studien og viste en $21 \%$ økning i dødelighet i lavoksygengruppen i forhold til høyoksygengruppen (17,3\% versus $14,4 \%$ ). Ved å analysere resultatene fra BOOST II-studien alene fant man hele $65 \%$ økning i dødelighet i lavoksygengruppen (13). Dette har ført til at mange av oss har følt behov for å komme med nye retningslinjer, hvor man anbefaler at prema- ture født før 28 ukers svangerskap, ikke bør ha en oksygenmetning mellom $85 \%$ og $89 \%$ (14). Hvor den optimale metningen skal ligge, er det nå ingen som tør angi. De fleste vil likevel mene at oksygenmetningen bør ligge mellom $90 \%$ og $94 \%$, men man har ikke lenger data for å underbygge dette.

\section{Resuscitering av nyfødte}

Resuscitering av nyfødte er en av de hyppigst utførte prosedyrer i medisinen. Man har estimert at opptil $10 \%$ av alle nyfødte trenger noe pustehjelp etter fødselen. I vår del av verden vil $3-5 \%$ av alle nyfødte trenge hjelp til ventilering med bag og maske rett etter fødselen (7). Dette svarer til 4-6,5 millioner barn på verdensbasis årlig.

Resuscitering av barn født til termin Nyfødte har tradisjonelt blitt resuscitert med $100 \%$ oksygen. Studier fra Pediatrisk forskningsinstitutt ved Rikshospitalet viste allerede for 20 år siden at det er mulig å resuscitere nyfødte griser like godt med luft som med oksygen (15). I 1993 publi- serte vi en klinisk pilotstudie hvor 42 nyfødte fra New Dehli ble resuscitert med luft og 42 med $100 \%$ oksygen. Studien viste at det er fullt mulig å resuscitere nyfødte med luft (16). Utover i 1990-årene fortsatte våre eksperimentelle studier, samtidig som vi organiserte en internasjonal multisenterstudie, RESAIR 2, hvor omtrent 600 barn fra ti sentre fra Egypt, Estland, Filippinene, India, Norge og Spania ble resuscitert enten med luft eller $100 \%$ oksygen (17). Til vår overraskelse fant vi at de barna som ble resuscitertmed luft, tok sitt første åndedrag omtrent 30 sekunder tidligere enn dem som fikk oksygen. Hjerteaksjonen og apgarskår steg også raskere når man brukte luft. Det var en $30 \%$ reduksjon i dødeligheten i favør av luft, men dette funnet var ikke statistisk signifikant.

Fra siste tusenårsskifte kom det flere eksperimentelle og kliniske data, både fra vår gruppe og fra andre, som viser at luft ikke bare er likeverdig med $100 \%$ oksygen for resuscitering, men også reduserer skader på hjerne, hjerte og nyrer $(18,19)$. Flere metaanalyser er publisert $(20,21)$. Den siste av 
disse oppsummerte ti studier med mer enn 2000 inkluderte barn (21). Den viste at luft i forhold til $100 \%$ oksygen reduserer dødeligheten med $31 \%$ (relativ risiko 0,$69 ; 95 \%$ KI 0,54-0,88). Dødeligheten faller fra $12,8 \%$ til $8,2 \%$. Statistisk sett blir ett barn reddet for hvert 25 . barn som ble resuscitert med luft istedenfor $100 \%$ oksygen. En separat analyse av de 449 barna som var født i Europa, viste en reduksjon i dødelighet med hele $68 \%$ i gruppen som resusciteres med luft - fra 3,9\% til 1,1\% (relativ risiko 0,$32 ; 95 \% \mathrm{KI} 0,12-0,84$ ).

\section{Resuscitering av for tidlig fødte barn} I $2008 \mathrm{kom}$ de første resultatene om bruk av oksygen for svært premature barn som trengte resuscitering $(22,23)$. Disse preliminære studiene viste at man ikke trenger å ventilere disse barna med en høy oksygenkonsentrasjon. Men det ser ut til at de minste og mest umodne barna ofte vil trenge noe oksygentilskudd. I påvente av to store kliniske studier - den ene ( $\mathrm{TO}_{2} \mathrm{RPIDO}$-studien) er i gang, og den andre (PRESOX-studien) venter på å bli igangsatt - er man derfor usikker på hvilken oksygenkonsentrasjon man skal gi til slike barn. De fleste vil i dag anbefale at man starter med mellom $21 \%$ og $30 \%$ oksygen og titrerer konsentrasjonen etter barnets respons.

\section{Diskusjon}

Oksygenbehandling av nyfødte har en lang og til dels smertelig historie. Behandlingen har i stor grad påført barn alvorlige iatrogene skader. Det har vært betydelig motstand mot å endre det rådende oksygenparadigmet (24). De siste ti årene har vi fått ny forståelse og bedre grunnlag for å oksygenbehandle for tidlig fødte barn, men vi er fortsatt i villrede om basale forhold, slik som hvilken oksygenmetning man skal sikte seg mot. Man vet heller ikke om oksygenmetningen skal differensieres etter barnas umodenhetsgrad, og om oksygenmetningen kanskje bør endres i løpet av de første ukene etter fødselen. De mange uløste spørsmålene kan bare besvares med store randomiserte studier. Dette vil ta tid, og svaret vil vi få kanskje først i begynnelsen av neste tiår.

Basert på et nylig estimat om at 814000 nyfødte på verdensbasis dør av fødsels- asfyksi (25), vil en $31 \%$ reduksjon i dødelighet indikere at 252000 barn $(95 \% \mathrm{KI}$ 146000 -374 000 barn) kan reddes på verdensbasis årlig ved å bruke luft i stedet for $100 \%$ oksygen. I tillegg vil omtrent en million barn fødes livløse (fresh stillbirths) og ofte ikke engang bli forsøkt resuscitert. En studie fra flere lavinntektsland antyder at kanskje $30 \%$ av disse barna kan reddes med enkel resuscitering med bag og maskeventilering med luft (26). Totalt kan derfor opp mot en halv million nyfødte reddes ekstra hvert år ved å ventilere dem med luft.

Langvarig og sjenerøs støtte fra en rekke kilder til våre forskningsprosjekter og en stor forskningsgruppe med flere enn 30 dedikerte doktorgradsstipendiater har i sterk grad bidratt til de omtalte forskningsresultatene.

\section{Ola Didrik Saugstad (f.1947)}

er professor i barnesykdommer ved Universitetet i Oslo, overlege i neonatologi og bestyrer ved Pediatrisk forskningsinstitutt.

Ingen oppgitte interessekonflikter.

\section{Litteratur}

1. Silverman WA. Retinopathy of prematurity: oxygen dogma challenged. Arch Dis Child 1982; 57: 731-3.

2. Northway WH Jr, Rosan RC. Radiographic features of pulmonary oxygen toxicity in the newborn: Bronchopulmonary dysplasia. Radiology 1968 91: $49-58$.

3. Obladen M. History of neonatal resuscitation. Part 2: oxygen and other drugs. Neonatology 2009; 95 . $91-6$

4. Gilbert C. Retinopathy of prematurity: a global perspective of the epidemics, population of babies at risk and implications for control. Early Hum Dev 2008; 84: 77-82.

5. Saugstad OD. Hypoxanthine as an indicator of hypoxia: its role in health and disease through free radical production. Pediatr Res 1988; 23: 143-50.

6. Guidelines for cardiopulmonary resuscitation and emergency cardiac care, IV: pediatric basic life support. JAMA 1992; 268: 2276-81

7. Perlman JM, Wyllie J, Kattwinkel J et al. Part 11: Neonatal resuscitation: 2010 International consensus on cardiopulmonary resuscitation and emergency cardiovascular care science with treatment tecommendations. Circulation 2010; 122 (suppl 2): S516-38.

8. Tin W, Milligan DW, Pennefather $P$ et al. Pulse oximetry, severe retinopathy, and outcome at one year in babies of less than 28 weeks gestation. Arch Dis Child Fetal Neonatal Ed 2001; 84: F106-10.

9. Saugstad OD, Aune D. In search of the optimal oxygen saturation for extremely low birth weight infants: a systematic review and meta-analysis. Neonatology 2011; 100: 1-8

10. Sweet DG, Carnielli V, Greisen G et al; European Association of Perinatal Medicine. European consensus guidelines on the management of neonatal respiratory distress syndrome in preterm infants 2010 update. Neonatology 2010; 97: 402-17.

11. Carlo WA, Finer NN, Walsh MC et al. Target ranges of oxygen saturation in extremely preterm infants. N Engl J Med 2010; 362: 1959-69.

12. Johnston ED, Boyle B, Juszczak E et al. Oxygen targeting in preterm infants using the Masimo SET Radical pulse oximeter. Arch Dis Child Fetal Neonatal Ed. E-publisert 6.3.2011.

13. Stenson B, Brocklehurst P, Tarnow-Mordi W. Increased 36-week survival with high oxygen saturation target in extremely preterm infants. N Engl J Med 2011; 364: 1680-2.

14. Saugstad OD, Speer CP, Halliday HL. Oxygen saturation in immature babies: Revisited with updated recommendations. Neonatology 2011; 100: $217-8$

15. Rootwelt T, Løberg EM, Moen A et al. Hypoxemia and reoxygenation with $21 \%$ or $100 \%$ oxygen in newborn pigs: changes in blood pressure, base deficit, and hypoxanthine and brain morphology. Pediatr Res 1992; 32: 107-13.

16. Ramji S, Ahuja S, Thirupuram S et al. Resuscitation of asphyxic newborn infants with room air or $100 \%$ oxygen. Pediatr Res 1993; 34: 809-12.

17. Saugstad OD, Rootwelt T, Aalen O. Resuscitation of asphyxiated newborn infants with room air or oxygen: an international controlled trial: the Resair 2 study. Pediatrics 1998; 102: e1.

18. Vento M, Sastre J, Asensi MA et al. Room-air resuscitation causes less damage to heart and kidney than $100 \%$ oxygen. Am J Respir Crit Care Med 2005; 172: 1393-8

19. Saugstad OD. Is oxygen more toxic than currently believed? Pediatrics 2001; 108: 1203-5

20. Tan A, Schulze A, O'Donnell CP et al. Air versus oxygen for resuscitation of infants at birth. Cochrane Database Syst Rev 2005; nr. 2: CD002273.

21. Saugstad OD, Ramji S, Soll RF et al. Resuscitation of newborn infants with $21 \%$ or $100 \%$ oxygen an updated systematic review and meta-analysis. Neonatology 2008; 94: 176-82

22. Escrig R, Arruza L, Izquierdo I et al. Achievement of targeted saturation values in extremely low gestational age neonates resuscitated with low or high oxygen concentrations: a prospective, randomized trial. Pediatrics 2008; 121: 875-81.

23. Wang CL, Anderson C, Leone TA et al. Resuscitation of preterm neonates by using room air or $100 \%$ oxygen. Pediatrics 2008; 121: 1083-9.

24. Saugstad OD. Resuscitation of newborn infants: from oxygen to room air. Lancet 2010; 376 : $1970-1$.

25. Black RE, Cousens S, Johnson HL et al. Global, regional, and national causes of child mortality in 2008: a systematic analysis. Lancet 2010: 375. 1969-87.

26. Carlo WA, Goudar SS, Jehan I et al. Newborn-care training and perinatal mortality in developing countries. N Engl J Med 2010; 362: 614-23.

Mottatt 8.8. 2011, første revisjon innsendt 13.9. 2011, godkjent 22.9. 2011. Medisinsk redaktør Petter Gjersvik. 